Proceedings of the 3rd International Congress APMAS2013, April 24-28, 2013, Antalya, Turkey

\title{
The Effect of Sliding Motion on Tribological Characteristics of PA6 and Zinc-Borate Reinforced PA6 Composites
}

\author{
A. AKINCI* \\ Sakarya University, Faculty of Engineering, Dept. of Metallurgy and Materials Engineering \\ Esentepe Campus, Sakarya, Turkey
}

\begin{abstract}
The tribological characteristic of pure polyamide (PA6) and $2.5 \%, 5 \%$ zinc borate $\left(\mathrm{Zn}_{3} \mathrm{BO}_{6}\right)$ filled (by wt) polyamide composites were comparatively evaluated under dry sliding conditions. Wear tests were carried out at room temperature under the loads of 5,10 , and $20 \mathrm{~N}$, and at the sliding speeds of $0.5,1.0$, and $1.5 \mathrm{~m} / \mathrm{s}$. The coefficients of friction of the materials were significantly influenced by an increase in zinc borate content. The friction coefficient of the PA6 was getting decreased from 0.420 to 0.188 with an increase in zinc borate content, depending on applied loads and sliding speeds. The results showed that the wear rates of pure PA6 and zinc borate filled polyamides increased with increase in loads. The wear rate of the PA6 decreased from $4.2 \times 10^{-6} \mathrm{~mm}^{3} / \mathrm{m} \mathrm{to}^{\circ}$ $5.0 \times 10^{-7} \mathrm{~mm}^{3} / \mathrm{m}$ with an increase in zinc borate content depending on applied loads.
\end{abstract}

DOI: $10.12693 /$ APhysPolA.125.475

PACS: 81.05.Qk, 12.60.Rc, 81.40.Pq

\section{Introduction}

Polymer and its based materials find ever increasing usage for numerous industrial applications in the sliding/ rolling components such as bearings, rollers, seals, gears, cams, wheels, piston rings, transmission belts, grinding mills, and clutches where their self lubricating properties are exploited to avoid the need for oil or grease lubrication with its attendant problems of contamination [1].

Inorganic particles are added to polymers in the expectation of obtaining unique physical and mechanical properties $[2,3]$. No tribological properties of polyamide-zinc borate composites have been described so far. Carrion et al. have recently described the tribological performance of polyamide nanocomposites containing $\mathrm{ZnO}$ nanoparticles $[4,5]$. Tribological performances of PA6 based coating materials used in space-based mechanical systems, aircraft propulsion and structures were investigated by Chen et al. [6]. Indumathi et al. observed that the tribological performance of PA6 showed moderate improvement due to cryo-treatment [7]. Inorganic particles have been widely used in recent years as fillers in polymers to improve their hardness and tribological performance [8].

In the present work, test materials have been prepared as series of filled PA6 materials with zinc borate filler $(0 \%, 2.5 \%$ and $5 \mathrm{wt} \%)$ to study the tribological effect of the filler content. The aim of this work was to study the effect of the zinc borate on the wear and friction behavior of PA6 as a good releasing mechanism for vehicles.

\section{Experimental}

$2.5 \mathrm{wt} \%$ and $5 \mathrm{wt} \%$ of zinc borate $(1-10 \mu \mathrm{m})$ were introduced to PA6 to investigate the wear relationships

\footnotetext{
*e-mail: akinci@sakarya.edu.tr
}

between the PA6 and zinc borate combinations. The polymer matrix material that was used in this study is a commercial grade PA6 Arkema Polymer Industry USA. Zinc borate obtained from Sigma-Aldrich Chemie GmbH was used in the polymer matrix composites. For tests, the samples were manufactured in the form of a pin the dimension of which is $6 \mathrm{~mm}$ in diameter and $60 \mathrm{~mm}$ in length. For production of zinc borate filled polymers, an injection apparatus was used with four different heating stages of $240,255,260,265^{\circ} \mathrm{C}$. Injection and molding pressure were chosen as $4 \mathrm{MPa}$ and $8 \mathrm{MPa}$, respectively. The mold temperature was fixed at $15^{\circ} \mathrm{C}$ and the pressure was applied for 3 composites. The friction and wear tests were realized using a pin-on-disk arrangement with the standards of ASTM G 99 and ASTM G 115 against the hardened AISI 4140 steel ( $58 \mathrm{HRc}$ ).

Wear tests parameters are given in Table. The hardness tests were performed on Instron S1 Durotech, digital shore D scale hardness tester with using the standard of ASTM D 2240. Rigaku D/MAX/2200/PC model XRD analyser $\left(\mathrm{Cu} K_{\alpha} 40 \mathrm{kV}, 30 \mathrm{~mA}\right)$ was used for characterization of zinc borate particles.

TABLE

Experimental process parameters of wear tests.

\begin{tabular}{c|c}
\hline \hline Parameters (units) & Experimental conditions \\
\hline applied load $[\mathrm{N}]$ & $5,10,20$ \\
sliding speeds $[\mathrm{m} / \mathrm{s}]$ & $0.5,1.0,1.5$ \\
temperature $\left[{ }^{\circ} \mathrm{C}\right]$ & $23 \pm 2$ \\
humidity $[\%]$ & $58 \pm 1$ \\
sliding distance $[\mathrm{m}]$ & 1000 \\
surface roughness, $\mathrm{Ra}[\mu \mathrm{m}]$ & 0.36
\end{tabular}

\section{Results and discussion}

XRD pattern of pure zinc borate particles is given in Fig. 1. Figure $2 \mathrm{a}$ and $\mathrm{b}$ presents the variation of the 
coefficient of frictions and wear rates of pure PA6 and zinc borate filled polyamides according to zinc borate content under the loads of 5,10 , and $20 \mathrm{~N}$ at the sliding speeds of $0.5,1.0$, and $1.5 \mathrm{~m} / \mathrm{s}$, respectively.

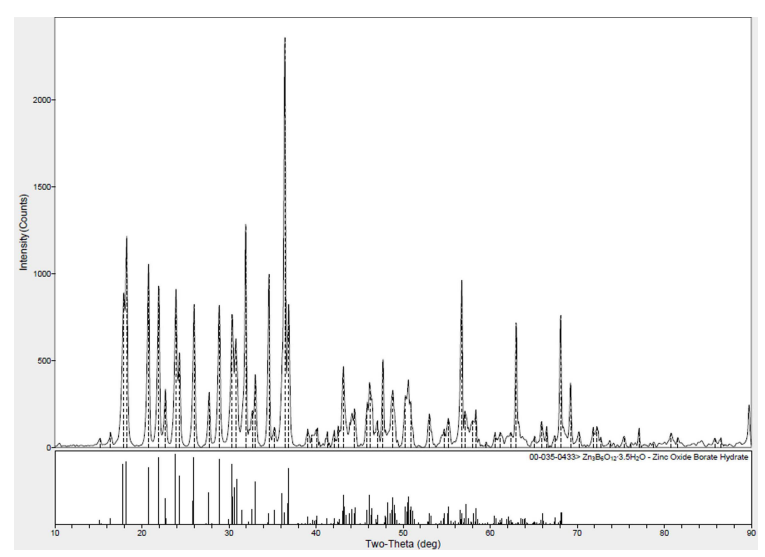

Fig. 1. XRD pattern of the pure zinc borate particles.

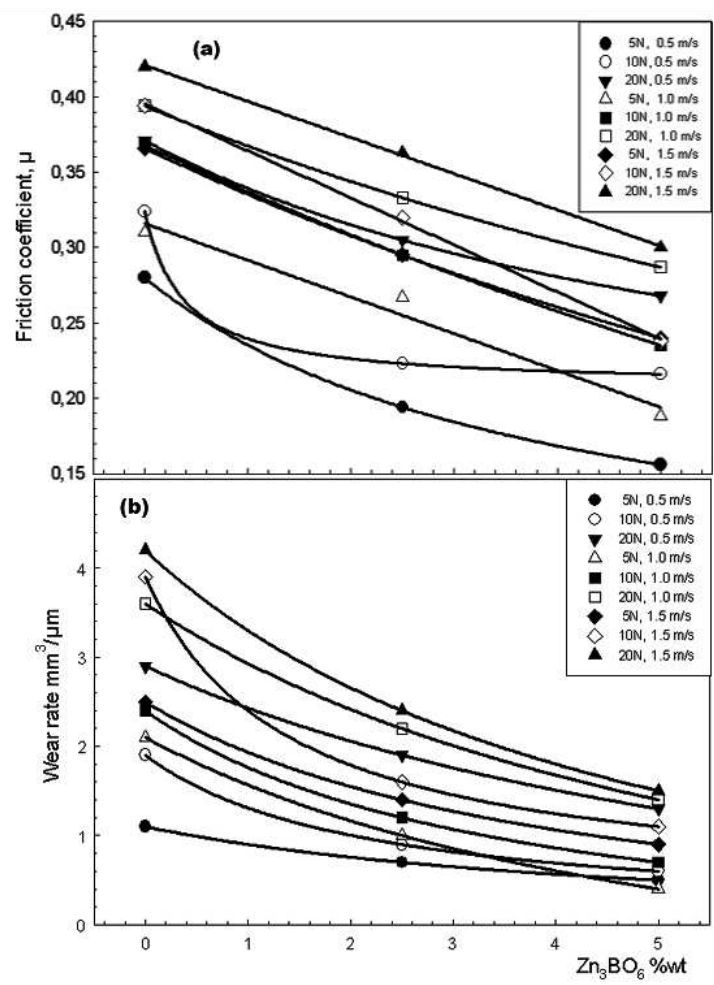

Fig. 2. Variation of coefficient of friction (a) and wear rate (b) of pure PA6 and zinc borate filled polyamides according to zinc borate content, applied load, and sliding speeds.

From Fig. 1 XRD peaks have given the results of the zinc borate formulation of the $\mathrm{Zn}_{3} \mathrm{~B}_{6} \mathrm{O}_{12} \cdot 3.5 \mathrm{H}_{2} \mathrm{O}$ compound. Tian et al. [9] found that the same X-ray diffraction pattern is given in Fig. 1. In the other articles, zinc borate was characterized by the same XRD pattern [10-12].
Figure 2 a reveals that a $300 \%$ increase in load value caused the increase in the coefficient of friction of PA6 and the zinc borate filled polyamide composites in the range of $33-72 \%, 25-53 \%$ and $15-25 \%$ depending on zinc borate content for $0.5,1.0$, and $1.5 \mathrm{~m} / \mathrm{s}$ sliding speeds, respectively. A $200 \%$ increase in the sliding speed caused the increase in the coefficient of friction of PA6 and the zinc borate filled polyamide composites in the range of $31-54 \%, 10-43 \%$ and $12-19 \%$ depending on zinc borate content for 5,10 , and $20 \mathrm{~N}$, respectively. The addition of zinc borate in the PA6 resulted in the decrease of the coefficient of friction in the range of $28-44 \%, 27-39 \%$ and $29-40 \%$ according to applied loads for $0.5,1.0$, and $1.5 \mathrm{~m} / \mathrm{s}$ sliding speeds, respectively. In general, as shown by the figures and calculated and discussed results, the coefficient of friction of zinc borate filled PA6 decreased with increase in zinc borate content for the all test conditions, and increase in the load value in the wear test caused the increase in coefficient of friction. An increase in the sliding speeds resulted in the increase of the coefficient of friction tested under the loads of $5 \mathrm{~N}$ and $10 \mathrm{~N}$, however, the coefficient of friction has not been affected effectively for the zinc borate filled polyamide composites tested under the loads of $20 \mathrm{~N}$ for all the sliding speeds. Unal and Mimaroglu [13] were found that the friction coefficient of the PA6 material was 0.09 under $20 \mathrm{~N}$ load and $0.88 \mathrm{~m} / \mathrm{s}$ sliding speed. In the report of Unal [14], the friction coefficient of PA6 was found between $0.37-$ 0.52 . And so, both of the studies friction coefficients were increased with increasing loads and speeds.

Figure $2 \mathrm{~b}$ reveals that a $300 \%$ increase in load value caused the increase in the wear rate of PA6 and the zinc borate filled polyamide composites in the range of 160 $171 \%$, 39-180\%, and 50-68\% depending on zinc borate content for $0.5,1.0$, and $1.5 \mathrm{~m} / \mathrm{s}$ sliding speeds, respectively. A $200 \%$ increase in the sliding speed caused the increase in the wear rate of PA6 and the zinc borate filled polyamide composites in the range of $80-127 \%, 56-105 \%$, and $15-45 \%$ depending on zinc borate content for 5,10 , and $20 \mathrm{~N}$, respectively. The addition of zinc borate in the PA6 resulted to decrease the wear rate in the range of 55$68 \%, 61-74 \%$ and $64-72 \%$ according to applied loads for $0.5,1.0$, and $1.5 \mathrm{~m} / \mathrm{s}$ sliding speeds, respectively.

In general, as shown by the figures and calculated and discussed results, the wear rate of zinc borate filled PA6 decreased with increase in zinc borate content for the all test conditions, and increase in the load value in the wear test caused the increase in wear rate. An increase in the sliding speeds caused the increase of the wear rate tested materials under the loads of 5,10 , and $20 \mathrm{~N}$. Unal et al. [15] determined that the abrasive wear rate of $30 \%$ wollastonite filled PA6 composite drops by $40 \%$ compared to pure PA6. The wear rates for wollastonite filled PA6 composites are ranging in $2.2 \times 10^{-5}-5.8 \times 10^{-5} \mathrm{~mm}^{3} / \mathrm{m}$. Tong et al. found that the abrasion resistance of the wollastonite filled UHMWPE composites was higher than that of the matrix material when the filler content was $20 \mathrm{wt} \%$, with the best abrasion resistance being obtained 
at a fiber content of $10 \%[16,17]$. Increase in zinc borate of the PA6 resulted in the increase of the polymer hardness and pressure strengths of the PA6-zinc borate filled polyamides beside the lubricant behaviors. Shore hardness of the pure PA6, $2.5 \mathrm{wt} \%$ and $5 \mathrm{wt} \%$ zinc borate filled PA6 composites was measured in this study as $73.58,74.4$, and 74.92 , respectively. This is in good agreement with literature [18].
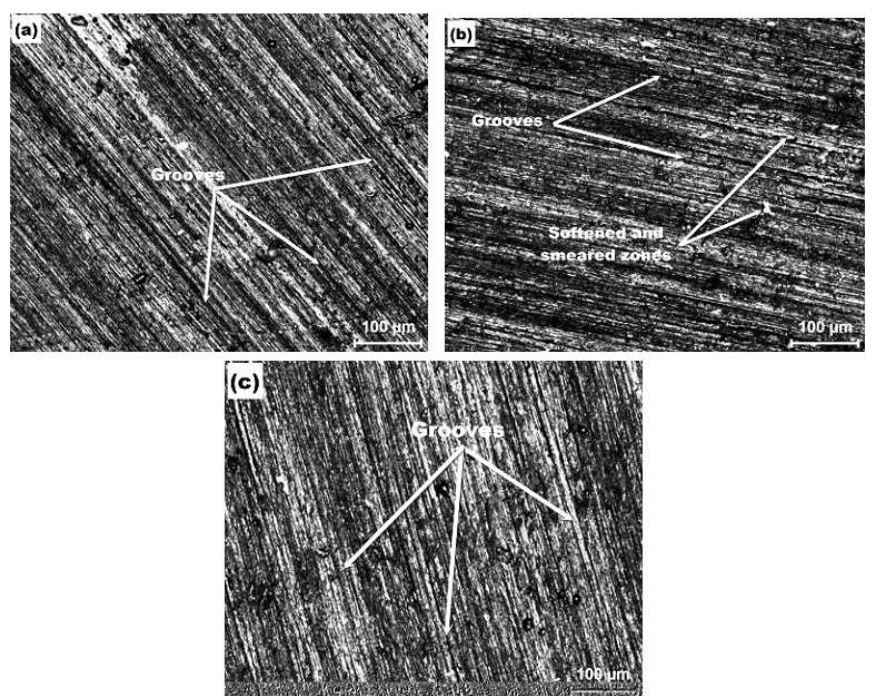

Fig. 3. Optical micrographs of worn surfaces of (a) pure PA6 and (b) PA6+2.5 wt\% zinc borate, (c) PA6 +5 wt $\%$ zinc borate at $0.5 \mathrm{~m} / \mathrm{s}$ sliding speed under $10 \mathrm{~N}$ load.

Figure $3 \mathrm{a}-\mathrm{c}$ shows the optical micrographs of worn pin surfaces of pure PA6, $2.5 \mathrm{wt} \%$ and 5 wt\% zinc borate filled PA6 at the $0.5 \mathrm{~m} / \mathrm{s}$ sliding speed under the load of 10 N. As it can be seen in Fig. 3, the worn surface of the zinc borate filled PA6 includes some micro scratches and some grooves and valleys on the worn surfaces. In addition these, some softened zone, especially low content zinc borate including polyamide composites, are shown on the wear track. Also, worn surfaces of the polyamide composites are getting roughened with an increase in zinc borate content. It is probable that zinc borate particles may be transferred on the steel counter face while of PA6 matrix were smeared on the slick line. These particles might cause the formation of micro scratching effect during the sliding tests, and some parts of the PA6 were softened with sliding effect and smeared the worn surfaces and produced some plastically deformed and so smeared zones. Carrion et al. observed that neat PA6 shows a wide and relatively polished wear track. Wear track shows a rougher surface with wear debris particles trapped in the worn area. Finally, PA6+ filler has a wider wear track with the parallel grooves [4].

\section{Conclusions}

As a result, the coefficient of friction of zinc borate filled PA6 decreased with increase in zinc borate content for the all test conditions, and increase in the load value in the wear test caused the increase in coefficient of friction. An increase in the sliding speeds resulted in the increase of the coefficient of friction tested under the loads of $5 \mathrm{~N}$ and $10 \mathrm{~N}$. The wear rate of zinc borate filled PA6 decreased with increase in zinc borate content for the all test conditions, and increase in the load value in the wear test caused the increase in wear rate. An increase in the sliding speeds caused the increase of the wear rate tested materials for all applied loads. The worn surface of the zinc borate filled PA6 includes some micro scratches and some grooves and valleys on the worn surfaces. In addition these, some softened zones, especially low content zinc borate including polyamide composites, are shown on the wear track. Also, worn surfaces of the polyamide composites are getting roughened with an increase in zinc borate content.

\section{References}

[1] M.A. Chowdhury, D.M. Nuruzzaman, in: Friction and Wear of Polymer and Composites, Ed. N. Hu, InTech Europe, New York 2012, p. 299.

[2] D.F. Charles, R. Gnanamoorthy, P. Ravindran, Wear 269, 565 (2010).

[3] W.G. Sawyer, K.D. Freudenberg, P. Bhimaraj, L.S. Schadler, Wear 254, 573 (2003).

[4] F.J. Carrion, A. Arribas, M.D. Bermudez, A. Guillamon, Eur. Polym. J. 44, 968 (2008).

[5] F.J. Carrion, J. Sanes, M.D. Bermudez, Wear 262, 1504 (2007).

[6] M.Y. Chen, Z. Bai, S.C. Tan, Surf. Coat. Technol. 151, 478 (2002).

[7] J. Indumathi, J. Bijwe, A.K. Ghosh, M. Fahim, N. Krishnaraj, Wear 225, 343 (1999).

[8] A. Akinci, S. Yilmaz, U. Sen, Appl. Compos. Mater. 19, 499 (2012).

[9] Y. Tian, Y. Guo, M. Jiang, Y. Sheng, B. Hari, G. Zhang, Y. Jiang, B. Zhou, Y. Zhu, Z. Wang, Mater. Lett. 60, 2511 (2006).

[10] J. Gao, H. Yin, A. Wang, T. Jiang, Powder Technol. 237, 537 (2012).

[11] J.X. Dong, Z.S. Hu, Tribol. Int. 31, 219 (1998).

[12] G.O. Cakal, Chem. Ind. Chem. Eng. Q. 18, 547 (2012).

[13] H. Unal, A. Mimaroglu, Mater. Des. 24, 183 (2003).

[14] H. Unal, Mater. Des. 25, 483 (2004).

[15] H. Unal, U. Sen, A. Mimaroglu, Appl. Compos. Mater. 15, 13 (2008).

[16] J. Tong, Y. Ma, R.D. Arnell, L. Ren, Compos. Part A-Appl. S. 37, 38 (2006).

[17] J. Tong, Y. Ma, M. Jiang, Wear 255, 734 (2003).

[18] J. Vina, M.A. Garcia, M.A. Castrillo, I. Vina, A. Arguelles, J. Thermoplast. Compos. 21, 279 (2008). 